\title{
Evaluation of Alveolar Bone Mandibular of Rats Obese Induced at Monosodium Glutamate Undergoing Modified Duodenal-Jejunal Bypass Surgery
}

\author{
Francielly Andressa Felipettia, Edson Oliveira Silva ${ }^{\mathrm{b}}$, Ana Lucia Carrinho Ayroza Rangele, \\ Carlos Augusto Nassar ${ }^{\mathrm{d}}$, Maria Lucia Bonfleure, Sandra Lucinei Balbo ${ }^{\mathrm{e}}$, \\ Cassiane Merigo Nascimento ${ }^{a}$, Patricia Oehlmeyer Nassar ${ }^{\mathrm{d}, \mathrm{f}}$
}

\begin{abstract}
Background: Obesity is a worldwide epidemic and its prevalence has doubled in recent years. Studies report that obesity may positively or negatively influence on bone mass resulting in formation or resorption. Furthermore, there is evidence suggesting that some obesity surgical treatments can also result in bone resorption. Thus, the aim of this study was to determine the consequences of monosodium glutamate (MSG)-induced obesity and modified duodenaljejunal bypass (modDJB) surgery on the mandibular alveolar bone of rats.
\end{abstract}

Methods: A total of 18 rats were divided into CON group $(\mathrm{n}=$ $6)$, MSG group $(n=6)$ and MDJB group $(n=6)$. During the first 5 days of life, the CON group received saline injections, and the MSG and MDJB groups received MSG injections to induce obesity. At 90 days, the MDJB group underwent modDJB surgery. After 2 months, all animals were euthanized; the right hemi-mandible was dissected, processed and submitted to histological analysis. The quantification of osteocytes and osteoclasts and the measurement of the distance between cementum enamel junction and bone crest (CEJ-BC) were performed. The data were analyzed and evaluated using ANOVA and Tukey's tests.

Manuscript accepted for publication August 27, 2014

\footnotetext{
${ }^{a}$ Biosciences and Health, State University of Western Parana (UNIOESTE), Cascavel Campus, PR, Brazil

${ }^{\mathrm{b}}$ State University of Western Parana (UNIOESTE), Cascavel Campus, PR, Brazil

${ }^{\mathrm{c} S}$ Stomatology and Oral Pathology, State University of Western Parana (UNIOESTE), Cascavel Campus, PR, Brazil

${ }^{\mathrm{d}}$ Periodontics, State University of Western Parana (UNIOESTE),

Cascavel Campus, PR, Brazil

'Physiology, State University of Western Parana (UNIOESTE),

Cascavel Campus, PR, Brazil

${ }^{f}$ Corresponding Author: Patricia Oehlmeyer Nassar, Dentistry School,

State University of Western Parana (UNIOESTE), Rua Pernambuco,

593, apto 504, Centro, Cascavel, PR 85810-020, Brazil.

Email: ponassar@yahoo.com
}

doi: http://dx.doi.org/10.14740/jem237w
Results: The results showed that MSG-obese rat had a lower mandibular alveolar bone resorption in comparison with the CON group. However, modDJB surgery contributed to the increase of bone resorption.

Conclusions: Based on these results, the present study concluded that this type of induction of hypothalamic obesity was beneficial to the mandibular bone, but modDJB surgery showed malefic effects on this bone.

Keywords: Obesity; Bariatric surgery; Bone; Mandible

\section{Introduction}

Obesity is a worldwide epidemic and its prevalence has duplicated over the past years. According to the World Health Organization, 200 million men and 300 million women are already considered obese [1]. The disease is characterized as a multifactorial disorder and it is the result of different exogenous factors: stress, anxiety [2], lack of physical activity, sedentarism, bad eating habits and high-fat food consumption [3]. However, there are also endogenous factors, such as craniopharyngiomas, which lead to alterations in the hypothalamo-pituitary axis and may be responsible for the development of obesity. But, in this case, these alterations result in a kind of disease called hypothalamic obesity $[4,5]$.

Bariatric surgery is a very effective tool in the treatment of obesity [6]. However, although there is vast scientific knowledge stating the benefits of bariatric surgery for exogenous obesity, its effects on the hypothalamic obesity still require further research [4].

Another issue that needs to be explained and is currently being widely researched and discussed is the changes that (exogenous or hypothalamic) obesity [7-9] and bariatric surgery can cause on bone mass [10].

Some authors report that obesity may be beneficial to bone mass and, consequently, favor bone formation $[8,11-$ 13], protect against fractures, prevent bone loss and osteoporosis $[9,12]$ and increase bone mineral density (BMD) in 


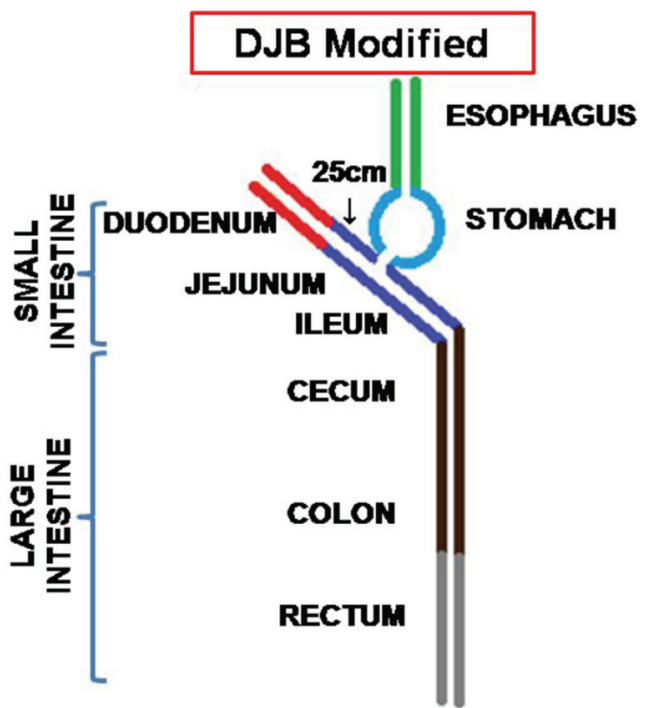

Figure 1. Schematic analysis of the gastrointestinal tract after modDJB surgery.

humans $[11,14]$. In experimental animals, obesity can also be beneficial in rats with monosodium glutamate (MSG)induced obesity as they presented a protective mechanism against mandibular bone resorption [7].

On the other hand, other authors have suggested that obesity may be harmful to bone mass because it is associated with increased bone resorption [15], low BMD and low bone quality, increasing the risk of fracture in humans [9]. In experimental studies, authors have shown that rats with high-fat-diet-induced obesity may present lower bone mineral content (BMC), which harms bone mass [16].

Further evidence shows that the proposed surgical treat- ment for obesity can also result in bone resorption, reduction in BMD, osteoporosis and increased risk of fracture in humans [15, 17-19] and significant loss of cancellous bone volume in animals [10].

Considering the divergent findings in the literature, it is possible to notice that, despite many studies on obesity and its surgical treatment, there are still gaps regarding its effects on bone tissue, and reason why further research is important. In addition, studies have shown that obesity and bariatric surgery cause changes on the femoral neck, lumbar spine $[14,15]$, forearm [15], tibia and radius [20]. No research to date has associated these two conditions with mandibular bone tissue, one of the tissues supporting the teeth, which was one aspect that motivated this research. Therefore, the aim of this study was to analyze the consequences of MSGinduced obesity and the changes caused on the mandibular alveolar bone in rats over a 2-month period after modified duodenal-jejunal bypass (modDJB) surgery.

\section{Materials and Methods}

\section{Animals}

We used 18 Wistar male rats obtained from the animal vivarium at State University of Western Parana (UNIOESTE) and maintained under controlled temperature $\left(23^{\circ} \mathrm{C} \pm 2{ }^{\circ} \mathrm{C}\right)$ and light conditions ( $12 \mathrm{~h} \mathrm{light/dark} \mathrm{cycle).} \mathrm{On} \mathrm{the} \mathrm{first} \mathrm{day} \mathrm{after}$ birth, the animals were randomly divided into the following groups. 1) Control group (CON: $\mathrm{n}=6$ ) was composed of animals that received daily subcutaneous saline injections (1.25 $\mathrm{mg} / \mathrm{g}$ body weight) in the cervical region during the first 5 days of life. The saline solution was prepared using 3.125

Table 1. Data for Body Size of Animals in the Groups Established Expressed in Grams (g) and Percentage of Body Weight (\%)

Groups

Body data

CON MSG MDJB

$\begin{array}{lccc}\text { Body weight }(\mathrm{g}) & 413.3 \pm 23.1^{\mathrm{a}} & 351.7 \pm 26.9^{\mathrm{b}} & 299.3 \pm 28.1^{\mathrm{c}} \\ \begin{array}{l}\text { Epididymal pads }(\% \text { body } \\ \text { weight) }\end{array} & 1.2 \pm 0.3^{\mathrm{a}} & 2.2 . \pm 0.3^{\mathrm{b}} & 2.0 \pm 0.2^{\mathrm{b}} \\ \begin{array}{l}\text { Retroperitoneal pads }(\% \\ \text { body weight) }\end{array} & 0.9 \pm 0.2^{\mathrm{a}} & 2.1 \pm 0.5^{\mathrm{b}} & 1.8 \pm 0.3^{\mathrm{b}}\end{array}$

The values expressed are means \pm standard deviation. Different letters indicate that the results are statistically different with $P<0.05$. Absence of letters indicates that there was no statistically significant difference. 


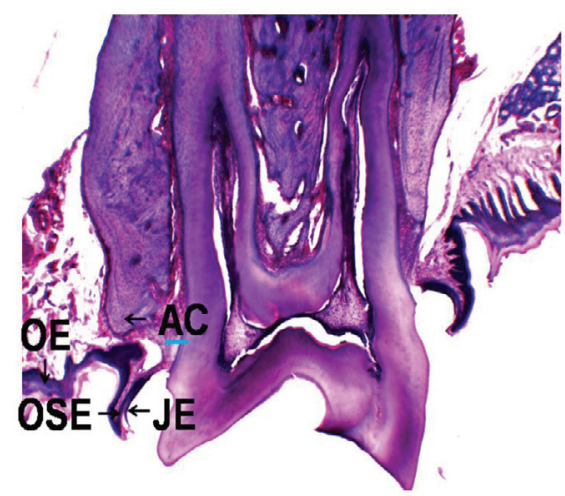

Figure 2. Representative photomicrograph of morphology of epithelial tissues and bone crest height of the groups studied. Note height of the alveolar crest (blue line) and normal appearance of the division of the oral, sulcular and junctional epithelium (hematoxylin and eosin, $\times 40$ ). AC: alveolar crest; JE: junctional epithelium; OE: oral epithelium; OSE: oral sulcular epithelium.

$\mathrm{g}$ of $\mathrm{NaCl}+25 \mathrm{~mL}$ of distilled water and applied with an insulin syringe. 2) MSG group (MSG: $n=6$ ) was composed of animals that received daily subcutaneous MSG injections ( $4 \mathrm{mg} / \mathrm{g}$ body weight) in the cervical region during the first 5 days of life to induce development of hypothalamic obesity. The solution was prepared using $6 \mathrm{~g}$ of $\mathrm{MSG}+25 \mathrm{~mL}$ of distilled water and applied with an insulin syringe. 3) MDJB group (MDJB: $n=6$ ) was composed of animals that also received daily subcutaneous MSG injections (4 mg/g body weight) in the cervical region during the first 5 days of life to induce development of hypothalamic obesity.

The rats were breastfed until the 21 st day of life. After weaning, they received water and commercial feed ad libitum.

\section{Bariatric surgery}

At 90 days, the animals in the MDJB group were submitted to modDJB surgery. For this, the animals were anesthetized with $1 \%$ isoflurane anesthetic (Instituto Biochimico Industria Farmaceutica Limitada, Itatiaia, RJ, Brazil) under flowing oxygen $(1 \mathrm{~mL} / \mathrm{min})$ and subjected to $\operatorname{modDJB}$ technique, a surgical technique similar to DJB [21], but with some modifications: reduction in the number of incisions and suture lines. Briefly, the duodenal stent was sutured using 7-0 polypropylene thread (Ethicon ${ }^{\circledR}$, Ethicon Division of Johnson and Johnson, Sao Jose dos Campos, SP, Brazil) with interrupted suture and invaginating suture. The duodenum was then deviated together with $25 \mathrm{~cm}$ of jejunum. After deviation, the jejunum was anastomosed to the stomach, and gastrojejunostomy was performed (Fig. 1) and sutured with interrupted suture and 7-0 polypropylene thread (Ethicon ${ }^{\circledR}$, Ethicon Division of Johnson and Johnson, Sao Jose dos Campos, SP, Brazil).

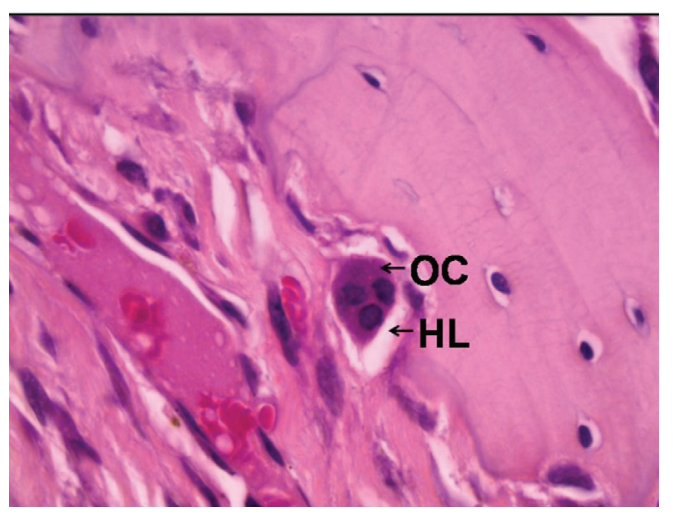

Figure 3. Representative photomicrographs of evidence of bone resorption in all groups studied. Note osteoclast in Howship's lacunae, indicating an area of bone resorption (hematoxylin and eosin, $\times 1,000$ ). HL: Howship's lacunae; OC: osteoclast.

\section{Evaluation of obesity, euthanasia and sample collection}

After 150 days (2 months after surgery), all animals (CON, MSG and MDJB groups) were weighed and euthanized by desensitization and decapitation. Next, the following were collected: periepididymal and retroperitoneal fats and the right hemi-mandible. Periepididymal and retroperitoneal fats were weighed separately to evaluate the accumulation of fat. The hemi-mandibles were fixed in $10 \%$ formalin solution for histological processing.

\section{Histological processing}

The right hemi-mandibles remained in $10 \%$ formalin solution for $24 \mathrm{~h}$. After this period, they were washed under running water for $1 \mathrm{~h}$ and immersed into a decalcification solution prepared with $85 \%$ formic acid $(85 \%$ formic acid P.A., code 288, lot 0907252, Vetec Quimica Fina, Rio de Janeiro, RJ, Brazil). After 30 days, we verified the expected degree of decalcification and then the parts were washed again under running water for $1 \mathrm{~h}$ and submitted to histological automatic processing for approximately $12 \mathrm{~h}$ (automatic tissue processor, Leica Microsystems ${ }^{\circledR}$ TP1020, Nussloch, Germany). Next, the parts were embedded in paraffin and the blocks were obtained (Paraffin Purified, code 1228, lot 1008459, Vetec Quimica Fina, Rio de Janeiro, RJ, Brazil). The paraffin blocks were cut with the aid of a semi-automatic microtome (Hestion ${ }^{\circledR}$, ERM3000, Daintree Scientific, St. Helens, Australia) to obtain $5 \mu \mathrm{m}$ thick sections. The histological sections were used for mounting the histological slides and stained with hematoxylin and eosin [22].

\section{Histomorphometric analysis}

The analysis of the histological sections was performed by 


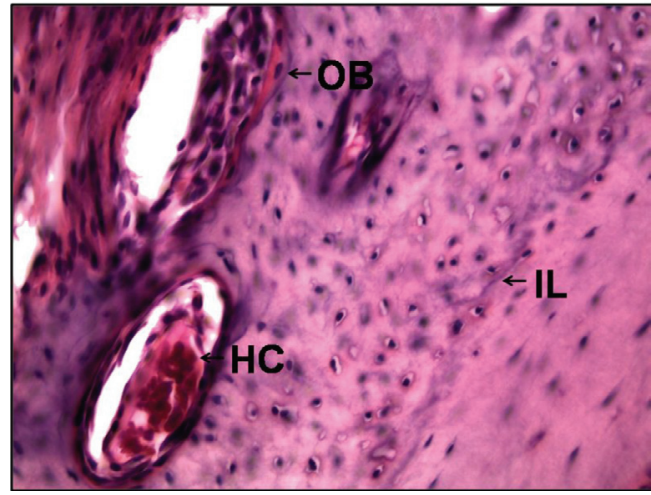

Figure 4. Representative photomicrographs of evidence of bone formation in all groups studied. Note areas of bone formation with presence of incremental lines, Haversian canal and osteoblasts (hematoxylin and eosin, x 400). HC: Haversian canal; IL: incremental lines; OB: osteoblasts.

a single examiner under blinded conditions with the aid of a light microscope (Leica Microsystems, Switzerland). The analysis consisted of two stages: the morphological and morphometric analyses. Morphological analysis was performed at $\times 40$ magnification and the following characteristics of each group were observed: integrity of epithelial tissues, presence of inflammatory infiltration and bone tissue characteristics. The morphometric analysis consisted of the following three stages: osteocyte count, osteoclast count and measurement of the distance between cement enamel junction and bone crest (CEJ-BC). Osteocyte and osteoclast count was performed by observing five consecutive visual fields of the mandibular buccal alveolar bone crest at $\times 1,000$ magnification. Two observations per field were made on two different days and the mean value was calculated for each animal and for each group. The CEJ-BC distance was measured using the images obtained through the Laz $\mathrm{Ez}^{\circledR}$ program. These measurements were repeated twice a day, on three different days, and then the mean value for each group was calculated.

\section{Statistical analysis}

Data were analyzed using ANOVA and Tukey's test by means of the BioEstat 4.0 and GraphPad Prism 5 software.

\section{Ethical aspects}

The study was approved by the Ethics Committee on Animal Experimentation and practical lectures (CEEAAP) at UNIOESTE by the protocol number 87/09.

\section{Results}

Effect of administration of MSG on body weight, percentage of fat in rats and consequences of modDJB surgery

The MSG injection reduced body weight in the MSG group by $14.9 \%$ in comparison with CON. Bariatric surgery further decreased this parameter by $14.9 \%$ in the MDJB group in comparison with the MSG group. The percentage of periepididymal and retroperitoneal fat was $72.8 \%$ and $140.7 \%$, respectively, higher in the MSG group than in the CON group. Bariatric surgery in the MDJB group did not change this parameter in comparison with the MSG group (Table 1).

\section{Morphologic analysis}

The CON, MSG and MDJB groups showed normal morphology of the oral, junctional and sulcular epithelium. The alveolar bone crest of all animals showed median thickness and height at the cervical third of the root (Fig. 2). The analysis of the bone crest at higher magnification $(\times 1,000)$ revealed Howship's lacunae with osteoclasts and evidence of bone resorption, however, less significant in the $\mathrm{CON}$ group, and MSG and MDJB groups (Fig. 3). In addition, we observed

Table 2. Osteocyte and Osteoclast Count in the Mandibular Alveolar Bone of Rats in the Established Groups Expressed in Units

\begin{tabular}{lll} 
Groups & Number of osteocytes (unit) & Number of osteoclasts (unit) \\
\hline CON & $49.6 \pm 15.5$ & $0.3 \pm 0.3$ \\
MSG & $57.3 \pm 8.8$ & $0.1 \pm 0.1$ \\
MDJB & $62.9 \pm 8.4$ & $0.2 \pm 0.2$ \\
\hline
\end{tabular}

The values represent the mean \pm standard deviation. Absence of letters indicates that there was no statistically significant difference. 


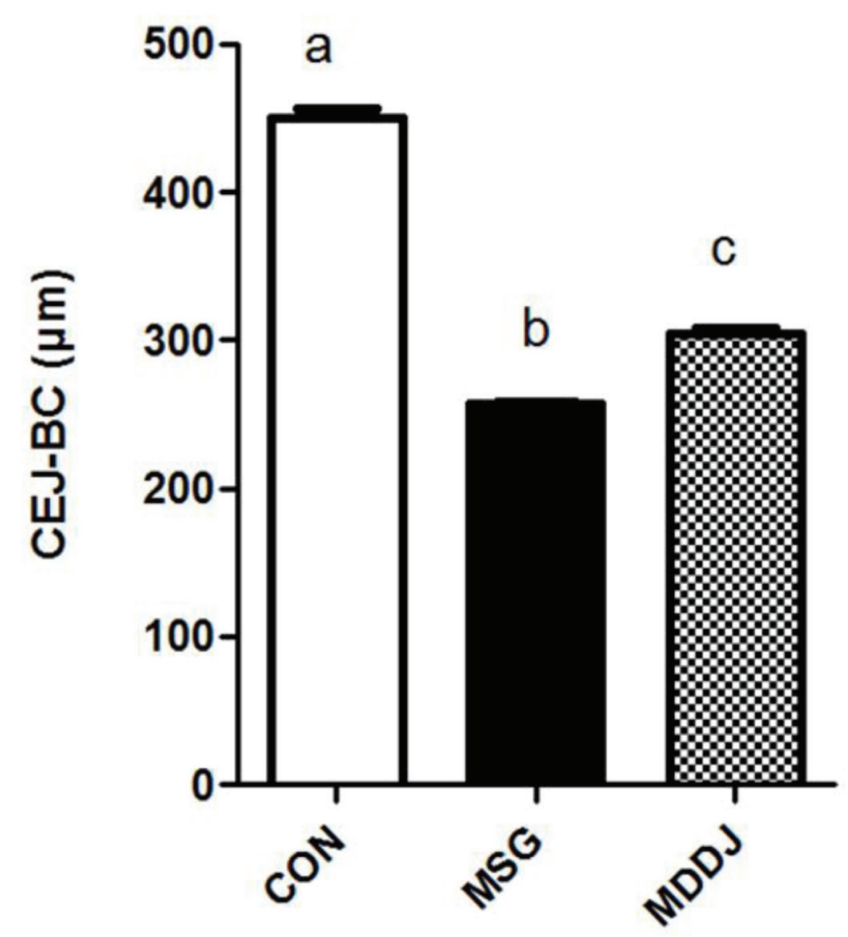

Figure 5. CEJ-BC distance of rats in the established groups expressed in micrometers $(\mu \mathrm{m})$. The values represent the mean \pm standard deviation. Different letters over the bars represent significant differences among groups $(P<0.01)$.

the appearance of incremental lines, organization of Haversian canals, and presence of osteoblasts aligned adjacent to the bone crest showing bone formation activity in all groups (Fig. 4). The underlying connective tissue of all rats showed scarce inflammation, mixed inflammatory infiltrate and predominantly neutrophilic inflammation located near the base of the junctional epithelium. Exocytosis of these cells also occurred in the junctional and sulcular epithelium, although in small quantities.

\section{Morphometric analysis}

The number of osteocytes and osteoclasts was similar in all groups studied (Table 2). The main findings were that the CEJ-BC measurement was $43 \%$ lower in the MSG group than in the $\mathrm{CON}$ group, indicating a reduction in bone resorption in the MSG group. After bariatric surgery, the MDJB group presented values $18.5 \%$ higher than in the MSG group (Fig. 5), suggesting an increase in the bone resorption in the MDJB group.

\section{Discussion}

The protocol of hypothalamic-induced obesity through the administration of MSG is well established in the literature. There are reports of using animal models for experimental obesity since the 1970s [23]. Studies have shown that the ad- ministration of high doses of MSG to neonatal rodents promotes accumulation of fat $[7,23]$ and decreases body weight in the MSG group in comparison with the control group [7, $24,25]$. These changes occur because of an increase in the concentration of insulin (hyperinsulinemia) in the animals that undergo MSG-induced obesity. Since insulin is a lipogenic hormone that helps the production of fat, these animals can experience increased fat accumulation. In addition, the activity of the sympathetic nervous system (SNS) was reduced in the animals in the MSG group. Since the SNS is responsible for inhibiting the release of insulin from the pancreas and promoting lipolysis (breakdown of fat) in white and brown adipose tissue, reducing its activity implies an increase in lipogenesis (synthesis of fatty acid and triglyceride) and accumulation of fat [24, 25]. Furthermore, MSG causes lesions in the arcuate nucleus, one of the areas responsible for maintaining the balance between consumption and waste of energy [4]. These lesions may impair the synthesis of the growth hormone-releasing hormone (GHRH), thus reducing the release of the growth hormone (GH). As a consequence, the low concentration of $\mathrm{GH}$ favors growth retardation, shorter bone length and inhibition of muscle mass [7, 24, 25]. As GH is a lipolytic hormone (helps breakdown fat), its low concentration favors increase in fat deposition [26]. Thus, when compared with the normal animals, animals submitted to MSG-induced obesity are lighter, but they present higher fat accumulation. In agreement with this information, the present study showed that the animals in the MSG group 
presented lower body weight and higher percentage of retroperitoneal and periepididymal fat than the CON group (Table 1).

With regard to bariatric surgery, the literature frequently reports results of weight loss after this procedure in humans with exogenous obesity [27]. However, despite the widespread recognition with regard to the consequences of bariatric surgery on the treatment of exogenous obesity, its effects on the hypothalamic obesity are still very limited. One of the reports in the literature showed that significant weight loss occurred in nine adolescents with hypothalamic obesity associated with craniopharyngioma after bariatric surgery [28]. However, other authors showed that a patient who developed hypothalamic obesity after resection of craniopharyngioma lost $49 \mathrm{~kg}$ in 2.5 years after undergoing Roux-Y gastric bypass. Significant weight loss after laparoscopic adjustable gastric banding and biliopancreatic diversion also occurred in other teenagers $[4,29]$. In the present study, modDJB interfered significantly on the body weight of rats with hypothalamic obesity and the animals' weight in the MDJB group decreased by $14.88 \%$ in comparison with those in the MSG group 2 months after the procedure. The malabsorption of nutrients is one of the explanations for this occurrence. According to the literature, malabsorptive bariatric surgeries, those that promote the diversion of a portion of the intestine, reduce the surface area of the intestine available for absorption $[17,19]$. Then, after the surgery, approximately $25 \%$ of proteins and $72 \%$ of fat were no longer absorbed. Consequently, zinc and lipossoluble vitamins that require dietary fat to be absorbed are also poorly absorbed. These factors can result in weight loss [5].

Morphological analysis of the alveolar bone crest in all groups showed normal characteristics represented by median thickness and height at the level of the cervical third of the root. In addition, all groups showed presence of areas of osteoblasts and less significant osteoclasts indicating bone formation and resorption. In normal physiological conditions, bone formation and resorption are in balance and the activity of osteoclasts is followed immediately by the activity of osteoblasts [30]. Therefore, in all groups, we found areas of bone formation and resorption.

The findings of the present study also showed normal morphology of the underlying connective tissues and oral, junctional and sulcular epithelium. But the presence of small quantity of inflammatory cells was found in the underlying connective tissue and exocytosis of these cells into the junctional and sulcular epithelium in all the groups studied. Researchers report that the standard diet offered to rodents for a period from 6 to 18 weeks favors the accumulation of bacterial plaque around the teeth [31]. As a result, some inflammatory cells are attracted to the underlying connective tissue and migrate to the junctional epithelium. Neutrophils are the first line of cells that arrive to the tissue being followed by small quantities of eosinophils, lymphocytes and plasma cells. His- tologically, the presence of bacteria and the recruitment of a few inflammatory cells did not cause significant lesions in the periodontium of rats fed on a standard diet [32]. It is suggested that the small quantity of inflammatory cells found in epithelial and connective tissues in all the groups studied is related to the accumulation of bacterial plaque caused by the standard diet. MSG-induced obesity and bariatric surgery caused no interference with these tissues.

Experimental studies on the association between obesity and bone mass are relatively common in the literature. Authors report that exogenous obesity, induced by a high-fat diet, in rats may harm the bone tissue of the tibia and reduce BMC [16]. This is probably because of the inflammatory nature of obesity itself. An increase in the number of adipocytes promotes the release of monocytechemotactic protein-1 (MCP-1), which in turn allows the influx of monocytes into the adipose tissue. Due to the release of colony-stimulating factor-1 (CSF-1) by the adipocytes, monocytes differentiate into active macrophages, which increase the expression of proinflammatory cytokines such as tumor necrosis factor- $\alpha$ (TNF- $\alpha$ ), interleucin 6 (IL-6) and interleucin 1 (IL-1) [33]. These cytokines are able to stimulate osteoclast activity through a mechanism that includes the action of the receptor activator of NF-kB ligand (RANKL) and receptor activator of NF-Kb (RANK), favoring bone resorption [9, 34].

On the other hand, a research conducted in rats with endogenous obesity (or hypothalamic obesity) induced by MSG reveals that the animals present lower bone resorption in comparison with the control group [7]. Similarly, the main findings of this study also showed that the CEJ-BC distance is smaller in the rats submitted to MSG-induced obesity, which indicates lower bone resorption when compared with the CON group. It is suggested that this happened because the obese animals in the MSG model appear to have a protective mechanism that can interfere with the process of bone remodeling. This mechanism may be associated with leptin and insulin, two hormones whose concentrations were increased in these animals [7]. There is evidence that these hormones play an important role in bone metabolism and favor bone formation when acting locally. Osteoblasts and osteoclasts have receptors for insulin. Thus, insulin is capable of increasing bone formation and decreasing bone resorption in vitro and in vivo [35]. Leptin can reduce the expression of RANK, stimulate the expression of osteoprotegerin (OPG), and inhibit osteoclast differentiation [36]. Thus, it is suggested that when leptin and insulin act locally on the bone tissue of animals with hypothalamic obesity, they promote less intense alveolar bone resorption, which is not true for animals with exogenous obesity.

Similar to obesity, bariatric surgery can also cause changes in bone mass. There are reports that the surgery in humans causes bone loss and increases risk of fractures [18] and in rats it reduces bone volume of the femur [10]. Another important result of the present study showed that significant 
bone loss of the mandibular alveolar bone crest occurred after modDJB surgery. The main explanations for the occurrence of bone loss after surgery remain obscure, but some factors may be involved in this mechanism, such as disorders of mineral metabolism and hormonal changes [15].

Mineral disorders are mainly related to calcium malabsorption [17]. The modDJB surgery promotes the deviation of the duodenum and part of the jejunum. This deviation results in malabsorption of iron, folic acid, vitamin B-12 and particularly calcium [6]. Low concentrations of calcium promote an increase in the concentrations of the parathyroid hormone (PTH), favoring bone resorption [19]. Furthermore, there are studies showing that bariatric surgery can cause low $25(\mathrm{OH}) \mathrm{D}$ concentrations [17], which may indicate vitamin $\mathrm{D}$ deficiency. As vitamin $\mathrm{D}$ is active in calcium metabolism, its poor absorption after surgery results in increased risk for the development of metabolic bone disease [19].

Adding to this, bariatric surgery also causes hormonal changes such as an increase in adiponectin [18] concentrations and decrease in glucagon-like peptide-2 (GLP-2) concentrations [19]. Increased adiponectin production favors the increase of bone resorption by the mechanism of RANK/ RANKL [18]. The GLP-2 would have a favorable effect on bone mass by decreasing bone resorption in vitro [35]. But since the levels of GLP-2 decrease after surgery [19], its beneficial effect is reduced and can lead to bone loss.

With respect to the quantification of cells, studies show that, under normal conditions, osteocytes are the most abundant cells present in the bone tissue [37]. A great quantity of osteocytes indicates bone maturity [38]. The increase in the quantity of osteoclasts is associated with bone resorption [39]. The present research found a high quantity of mandibular alveolar bone osteocytes in all the groups and a small quantity of osteoclasts, but no significant difference was found among the groups, which indicates that neither MSGinduced obesity nor bariatric surgery significantly caused changes in the number of bone cells.

Based on these results, the present study showed that experimental hypothalamic obesity induced by MSG was beneficial to bone mass as it decreases the CEJ-BC distance, indicating a reduction in mandibular alveolar bone resorption. However, MSG-induced obesity rats who underwent modDJB showed an increase of this distance, suggesting a rise in bone resorption 2 months after surgery. Further studies need to be conducted to ascertain the mechanisms responsible for bone protection in MSG-induced obesity and bone resorption after modDJB.

\section{References}

1. World Health Organization. Obesity and overweight, May 2012. Media Centre. Disponivel em: <http://www. who.int/mediacentre/factsheets/fs311/en/index.html $>$. Acesso em: 16 Jun 2012, 16:30:30.

2. Ogden J, Clementi C. The Experience of Being Obese and the Many Consequences of Stigma. J Obes. 2010;2010:1-9.

3. Pereira LO, Francischi RP, Lancha Jr AH. Obesidade: Hábitos Nutricionais, Sedentarismo e Resistência à Insulina. Arq Bras Endocrinol Metabol. 2003;47:111-127.

4. Bingham NC, Rose SR, Inge TH. Bariatric surgery in hypothalamic obesity. Front Endocrinol (Lausanne). 2012;3:23.

5. Bordalo LA, Teixeira TF, Bressan J, Mourao DM. [Bariatric surgery: how and why to supplement]. Rev Assoc Med Bras. 2011;57(1):113-120.

6. Marsicano JA, Grec PG, Belarmino LB, Ceneviva $\mathrm{R}$, Peres SH. Interfaces between bariatric surgery and oral health: a longitudinal survey. Acta Cir Bras. 2011;26(Suppl 2):79-83.

7. Brandelero S, Jr., Bonfleur ML, Ribeiro RA, Vanzela EC, Nassar CA, Nassar PO, Balbo SL. Decreased TNFalpha gene expression in periodontal ligature in MSGobese rats: a possible protective effect of hypothalamic obesity against periodontal disease? Arch Oral Biol. 2012;57(3):300-306.

8. Bandeira F. [Does obesity really strengthens the bones?]. Arq Bras Endocrinol Metabol. 2007;51(6):895-897.

9. Cao JJ. Effects of obesity on bone metabolism. J Orthop Surg Res. 2011;6:30.

10. Stemmer K, Bielohuby M, Grayson BE, Begg DP, Chambers AP, Neff C, Woods SC, et al. Roux-en-Y gastric bypass surgery but not vertical sleeve gastrectomy decreases bone mass in male rats. Endocrinology. 2013;154(6):2015-2024.

11. Cobayashi F, Lopes LA, Taddei JA. [Bone mineral density in overweight and obese adolescents]. J Pediatr (Rio J). 2005;81(4):337-342.

12. Santos LC, Cintra IP, Fisberg M, Castro ML, Martini LA. [Association among weight loss, bone mass, body composition and dietary intake of post-pubertal obese adolescents]. Arq Bras Endocrinol Metabol. 2008;52(6):1001-1008.

13. Van Coeverden SC, De Ridder CM, Roos JC, Van't Hof MA, Netelenbos JC, Delemarre-Van de Waal HA. Pubertal maturation characteristics and the rate of bone mass development longitudinally toward menarche. J Bone Miner Res. 2001;16(4):774-781.

14. Silva HG, Mendonca LM, Conceicao FL, Zahar SE, Farias ML. Influence of obesity on bone density in postmenopausal women. Arq Bras Endocrinol Metabol. 2007;51(6):943-949.

15. Pereira FA, de Castro JA, dos Santos JE, Foss MC, Paula FJ. Impact of marked weight loss induced by bariatric surgery on bone mineral density and remodeling. Braz J Med Biol Res. 2007;40(4):509-517. 
16. Chen JR, Lazarenko OP, Wu X, et al. Obesity Reduces Bone Density Associated with Activation of PPARc and Suppression of Wnt/b-Catenin in Rapidly Growing Male Rats. PloS one. 2010;5:1-13.

17. Fleischer J, Stein EM, Bessler M, Della Badia M, Restuccia N, Olivero-Rivera L, McMahon DJ, et al. The decline in hip bone density after gastric bypass surgery is associated with extent of weight loss. J Clin Endocrinol Metab. 2008;93(10):3735-3740.

18. Viegas M, Vasconcelos RS, Neves AP, Diniz ET, Bandeira F. Bariatric surgery and bone metabolism: a systematic review. Arq Bras Endocrinol Metabol. 2010;54(2):158-163.

19. Williams SE. Metabolic bone disease in the bariatric surgery patient. J Obes. 2011;2011:634614.

20. Pollock NK, Laing EM, Baile CA, Hamrick MW, Hall $\mathrm{DB}$, Lewis RD. Is adiposity advantageous for bone strength? A peripheral quantitative computed tomography study in late adolescent females. Am J Clin Nutr. 2007;86(5):1530-1538.

21. Rubino F, Marescaux J. Effect of duodenal-jejunal exclusion in a non-obese animal model of type 2 diabetes: a new perspective for an old disease. Ann Surg. 2004;239(1):1-11.

22. Junqueira LCU, Junqueira LMMS. Tecnicas basicas de citologia e histologia. 1. ed. Sao Paulo: Santos, 1983; p. 123.

23. Bunyan J, Murrell EA, Shah PP. The induction of obesity in rodents by means of monosodium glutamate. Br J Nutr. 1976;35(1):25-39.

24. Lucinei Balbo S, Gravena C, Bonfleur ML, de Freitas Mathias PC. Insulin secretion and acetylcholinesterase activity in monosodium l-glutamate-induced obese mice. Horm Res. 2000;54(4):186-191.

25. Balbo SL, Grassiolli S, Ribeiro RA, Bonfleur ML, Gravena C, Brito Mdo N, Andreazzi AE, et al. Fat storage is partially dependent on vagal activity and insulin secretion of hypothalamic obese rat. Endocrine. 2007;31(2):142-148.

26. Roemmler J, Kuenkler M, Otto B, Arafat AM, Bidlingmaier M, Schopohl J. Influence of long-term growth hormone replacement on leptin and ghrelin in $\mathrm{GH}$ deficiency before and after glucose load. Regul Pept. 2009;158(1-3):40-46.
27. Karmali S, Johnson Stoklossa C, Sharma A, Stadnyk J, Christiansen S, Cottreau D, Birch DW. Bariatric surgery: a primer. Can Fam Physician. 2010;56(9):873-879.

28. Gatta B, Nunes ML, Bailacq-Auder C, Etchechoury L, Collet D, Tabarin A. Is bariatric surgery really inefficient in hypothalamic obesity? Clin Endocrinol (Oxf). 2013;78(4):636-638.

29. Hochberg I, Hochberg Z. Expanding the definition of hypothalamic obesity. Obes Rev. 2010;11(10):709-721.

30. Silva I, Branco JC. Rank/Rankl/opg: literature review. Acta Reumatol Port. 2011;36(3):209-218.

31. Aguirre JI, Akhter MP, Kimmel DB, Pingel J, Xia X, Williams A, Jorgensen M, et al. Enhanced alveolar bone loss in a model of non-invasive periodontitis in rice rats. Oral Dis. 2012;18(5):459-468.

32. Lindhe J, Karring T, Lang NP. Tratado de Periodontia Clínica e Implantodontia Oral. 3. ed. Rio de Janeiro: Guanabara Koogan, 1997; p. 720.

33. Weisberg SP, McCann D, Desai M, Rosenbaum M, Leibel RL, Ferrante AW, Jr. Obesity is associated with macrophage accumulation in adipose tissue. J Clin Invest. 2003;112(12):1796-1808.

34. Raska O, Bernaskova K, Raska I, Jr. Bone metabolism: a note on the significance of mouse models. Physiol Res. 2009;58(4):459-471.

35. Walsh JS, Henriksen DB. Feeding and bone. Arch Biochem Biophys. 2010;503(1):11-19.

36. Holloway WR, Collier FM, Aitken CJ, Myers DE, Hodge JM, Malakellis M, Gough TJ, et al. Leptin inhibits osteoclast generation. J Bone Miner Res. 2002;17(2):200209.

37. Li W, Yeo LS, Vidal C, McCorquodale T, Herrmann M, Fatkin D, Duque G. Decreased bone formation and osteopenia in lamin a/c-deficient mice. PLoS One. 2011;6(4):e19313.

38. Kurikchy MQ, Al-Rawi NH, Ayoub RS, Mohammed SS. Histological evaluation of bone healing using organic bovine bone in combination with platelet-rich plasma (an experimental study on rabbits). Clin Oral Investig. 2013;17(3):897-904.

39. Spolidorio LC, Nassar PO, Nassar CA, Spolidorio DM, Muscara MN. Conversion of immunosuppressive monotherapy from cyclosporin a to tacrolimus reverses bone loss in rats. Calcif Tissue Int. 2007;81(2):114-123. 